\title{
Lack Of Timeliness, Noise And Transitory Components In Earnings As Explanations For The Apparent Decline In The Value Relevance Of Earnings
}

\author{
L. Dwight Sneathen, Jr., Georgia Southern University, USA
}

\begin{abstract}
Prior studies identify three factors that contribute to the low contemporaneous association between returns (prices) and earnings: lack of timeliness of earnings capturing value relevant information, noise in earnings, and transitory elements in earnings. This study seeks to identify whether these factors contribute to the observed inter-temporal decline in the contemporaneous association between returns (prices) and earnings documented in recent literature. Prior studies do not explicitly examine the affect of these factors on the inter-temporal decline, and the extant evidence is mixed. Empirical evidence presented here indicates that lack of timeliness of earnings and value-irrelevant noise in earnings have increased over time, both contributing to the documented inter-temporal decline in the contemporaneous association between returns (prices) and earnings.
\end{abstract}

Keywords: Value Relevance; Timeliness; Noise

\section{INTRODUCTION}

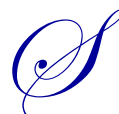

everal studies have empirically documented an inter-temporal decline in the contemporaneous association between returns (prices) and earnings (Collins, Maydew and Weiss 1997; Lev and Zarowin 1999; Francis and Schipper 1999; Ely and Waymire 1999). These studies have produced mixed results in their attempts to identify factors responsible for this decline. This study seeks to examine the contribution of three factors identified in prior literature that contribute to the low contemporaneous return (price)-earnings association: lack of timeliness of earnings, noise in earnings, and transitory components in earnings (Kothari 2000). Collins, Kothari, Shanken, and Sloan (1994) argue that lack of timeliness is potentially less of a concern than value-irrelevant noise.

We do not, however, advocate a change in the historical cost accounting measurement process to improve its timeliness. The reason is that attempts to improve timeliness entail trading off objectivity and verifiability of accounting numbers and require greater reliance on the managers' estimates of future cash flows, which are likely to be biased and noisy. (p. 321)

Thus, evidence of the contribution of each of these factors towards the inter-temporal decline in the contemporaneous association between prices and earnings will be useful in assessing the nature of the problem and whether any changes are necessary.

Prior literature examines specific determinants that relate to lack of timeliness, such as R\&D intensity and transitory earnings such as non-recurring items; however, it does not address the affect of changes in valueirrelevant noise on the inter-temporal decline in the contemporaneous association between returns (prices) and earnings. Further, the results provided for variables examining the lack of timeliness and transitory earnings produce mixed results. Using a different approach, this study examines the aggregate affect of each of the three factors and provides more powerful tests of their contribution to the decline in the contemporaneous association. 
First, to measure lack of timeliness, this study uses methods similar to Collins and Kothari (1989), Kothari and Sloan (1992), and Ali and Hwang (2000). The results show that the lack of timeliness of earnings increases significantly over time. After controlling for the effect of lack of timeliness on the contemporaneous association between returns (prices) and bottom line earnings, as is done in Ali and Hwang (2000), this study finds the contemporaneous association continues to exhibit a decline over time. This suggests that value-irrelevant noise and changes in the transitory component of earnings also contribute to the documented inter-temporal decline in the contemporaneous price-earnings association. Finally, transitory components (i.e., extraordinary items, discontinued operations, and cumulative effect of changes in accounting principles) and special items are removed from bottom line earnings to control for the effect of transitory earnings (Collins et al. 1997). The above analysis is repeated with this measure of CORE earnings, where lack of timeliness of CORE earnings is found to exhibit an increase over time. After controlling for the lack of timeliness, the contemporaneous association between returns (prices) and CORE earnings shows a decline over time, suggesting that value-irrelevant noise, by itself, may also be contributing to the observed decline in the contemporaneous association between returns (prices) and earnings.

\section{Factors Affecting the Contemporaneous Association between Returns (Prices) and Earnings}

Lev and Zarowin (1999) is one of several studies documenting an apparent decline in the ability of earnings to explain market prices. ${ }^{1}$ Their evidence indicates a decline in the R-squared for returns regressed against earnings. Collins, Maydew, and Weiss (1997) also document a decline in the incremental explanatory power of earnings using a price model with earnings and book values as explanatory variables. Collins, Kothari, Shanken, and Sloan (1994) and Kothari (2000) identify three factors that contribute to the low contemporaneous association between returns (prices) and earnings - lack of timeliness of earnings, noise in earnings, and transitory earnings. Inter-temporal changes in these three factors may have led to the observed inter-temporal decline in the contemporaneous association between returns (prices) and earnings.

\section{Lack of Timeliness}

The lack of timeliness of earnings results from accounting convention that is built upon the principles of verifiability, reliability and conservatism. Where market prices impound information without recognition restrictions, accounting recognition requirements create a delay in the ability of earnings to capture the economic effects of certain transactions, such as R\&D, sales commitments, and contracts, as well as any benefits garnered through corporate restructuring. The net benefits of these expenditures will be recognized in future earnings when the transactions clear recognition hurdles. Thus, current period earnings will be associated to prior period returns. There are several factors that could contribute to an inter-temporal change in the lack of timeliness of earnings, such as changes in firm characteristics, changes in accounting procedures, and changes in the information environment.

\section{Change in Firm Characteristics}

Prior literature examines lack of timeliness by looking at changes in the number of firms in intangible intensive industries as well as changes in the R\&D intensity of firms. Collins et al. (1997) document an increase, over time, in the proportion of firms involved in intangible intensive industries; however, this measure obtains an insignificant coefficient in a regression where the dependent variable is incremental explanatory power of earnings. Lev and Zarowin (1999) use R\&D intensity as a more specific measure of intangible activity. They find an increase in the mean R\&D intensity of firms over time, and firms increasing their R\&D intensity reflect decreases in the explanatory power of earnings. Firms retaining a constant level of R\&D intensity exhibit no changes in explanatory power.

\section{Changes in Accounting Procedures}

Post-retirement employee benefits, such as medical and dental insurance, are an example where accounting procedure changes altered recognition criteria, and therefore the timing of earnings capturing the affect of firm obligations. SFAS 106, introduced in 1990, required adherence to a more accrual-based recognition of post-

${ }^{1}$ Other studies include Ely and Waymire (1999), Francis and Schipper (1999) and Collins, Maydew and Weiss (1997). 
retirement benefits reducing the lack of timeliness of earnings. Periodic service cost is now computed and expensed each year based upon the portion of the benefit obligation attributed to employee service during the period. This differs from the pay as you go method (cash basis) used previously where expenses were recognized when claimed. This example suggests that accounting procedure changes over time may influence the lack of timeliness of earnings.

\section{Changes in the Information Environment}

Changes in the information environment could impact the timing of information being impounded into prices. Studies have clearly documented an increase in the proportion of the equity market held by institutional investors from below 5\% in 1945 to over 50\% in 1993 (i.e., Jennings, Schnatterly, and Seguin, 2002). Ayers and Freeman (2000) show that higher levels of institutional ownership and analyst following result in information being impounded into prices earlier. They argue that market participants, such as institutional investors, possess superior information analysis skills or have access to more detailed and timely information. ${ }^{2}$ In addition, the availability and frequency of information has changed dramatically over the past few years. Growth of the Internet and cable television has provided all investors with access to a great deal of information on market-wide and firm specific topics. Prices are likely to be leading earnings to a greater degree due to changes in the composition of investors in the market as well as changes in the timing and availability of information.

Prior literature has examined a limited set of determinants and provides inconsistent support for the lack of timeliness of earnings affecting the contemporaneous association between returns (prices) and earnings in the intertemporal setting. This study will use a more general measure of lack of timeliness in order to capture this affect. In order to assess whether lack of timeliness contributes to the decline in contemporaneous association between returns (prices) and earnings over time, the following hypothesis is presented in null form:

H1: Changes in the lack of timeliness of earnings over time are not responsible for the observed inter-temporal decline in the contemporaneous association between returns (prices) and earnings.

\section{Transitory Components in Earnings}

There are several elements of accounting that can introduce transitory components into earnings, such as negative earnings and non-recurring items (extraordinary items, special items and discontinued operations). Elliot and Hanna (1996) and Collins et al. (1997) document that the market considers items below income from continuing operations as transitory elements in earnings and that the propensity of firms to report these items is increasing. Collins et al. (1997) argue that special items are also likely to be transitory and are increasing over time. Investors place less weight on transitory components than on more permanent earnings. When the transitory and permanent components of earnings are not allowed to obtain separate coefficients, the explanatory power of the model reduces (Basu, 1997). If the proportion of earnings which is transitory increases over time, then this mis-specification will become more severe, resulting in an apparent decline in the contemporaneous association between returns (prices) and earnings. Collins et al. (1997) show that their variable that captures transitory items $\left(\mathrm{ONE}^{3}\right)$ does explain some of the inter-temporal decline in the explanatory power of earnings.

\section{Value-Irrelevant Noise}

Value-irrelevant noise is created when managerial estimates of the impact of a transaction on earnings differ from the markets'. Value-irrelevant noise may have changed over time due to modifications in accounting methodologies increasing the number of estimates used in the earnings measurement process. Prior to the implementation of SFAS 106, the cash basis of recognition for post-retirement benefits did not require any estimation; therefore, there were no differences in market and managerial assessments of these expenditures. Under the new reporting requirement, management is required to use several estimates in order to determine service cost

\footnotetext{
${ }^{2}$ Recently the SEC established Regulation FD which prohibits firms from providing value relevant information to selected parties, and was introduced to address the non-public conference calls and management interviews granted to certain parties. Apparently the SEC recognized the increase over time in the superior information available to certain investors.

${ }^{3}$ This variable is equal to the sum of extraordinary items, discontinued operations, and special items.
} 
and other aspects of post-retirement expense. These estimations include expected employee life span, rate of change of medical care costs, rates of utilization, discount rates, and employee turnover. This example clearly illustrates an increase in the use of estimates that can induce noise in earnings if the market assessment of the liability differs from the recognized liability.

Acquiring direct measures of either transitory earnings or value-irrelevant noise is an empirical obstacle. This study documents the effect of these two factors on the inter-temporal decline in the contemporaneous association of returns (prices) and earnings by controlling for the lack of timeliness factor to see if the explanatory power of earnings still declines over time. The following hypothesis is presented in null form:

H2: Changes in value-irrelevant noise and transitory components of earnings over time are not responsible for the observed inter-temporal decline in the contemporaneous association between returns (prices) and earnings.

This study also examines the affect of changes in value-irrelevant noise on the observed decline in the contemporaneous association between returns (prices) and earnings. For this purpose, CORE earnings is used as a control for transitory components in earnings. CORE earnings is defined as net income less extraordinary items, income from discontinued operations, and special items. The following hypothesis is presented in null form:

H3: Changes in value-irrelevant noise over time contribute to the observed inter-temporal decline in the contemporaneous association between returns (prices) and earnings.

\section{RESEARCH DESIGN}

\section{Measurement of Timeliness}

Two different tests are conducted to examine temporal change in the degree to which prices lead earnings. First, Collins and Kothari (1989) suggest the following model to document the lead-lag relationship between prices and earnings:

$\Delta X_{\mathrm{it}} / \mathrm{P}_{\mathrm{it}-1}=\gamma_{0}+\gamma_{1} \mathrm{R}_{\mathrm{it}-1}+\gamma_{2} \mathrm{R}_{\mathrm{it}}$

The dependent variable is the change in earnings per share before extraordinary items scaled by price at the beginning the year. The independent variables are 12-month cumulative abnormal returns for the current and prior period ending three months after the end of the fiscal year. They argue that a significant coefficient on prior period returns provides evidence of prices leading earnings. They estimate the model separately for small, medium, and large firms and show that the extent of lead-lag varies with firm size. follows:

The author is interested in how this lead-lag relationship varies over time, so equation (1) is modified as

$$
\Delta \mathrm{X}_{\mathrm{it}} / \mathrm{P}_{\mathrm{it}-1}=\gamma_{0}+\gamma_{1} \mathrm{R}_{\mathrm{it}-1}+\gamma_{2} \mathrm{R}_{\mathrm{it}}+\gamma_{3} \mathrm{TIME}^{*} \mathrm{R}_{\mathrm{it}-1}+\gamma_{4} \mathrm{TIME}^{*} \mathrm{R}_{\mathrm{it}}+\sum \gamma_{5, \mathrm{t}} \mathrm{Year}_{\mathrm{it}}+\varepsilon_{\mathrm{it}}
$$

TIME takes on values of 1 to $\mathrm{T}$ where $\mathrm{T}$ is the number of sample years and the Year variable represents a vector of dummy variables for the year of the observation. Coefficients $\gamma_{3}$ and $\gamma_{4}$ will provide an indication of a change in the return-earnings association over time. If information impounded into prior period returns increases over time, then a positive coefficient will obtain for $\gamma_{3}$. A negative coefficient on $\gamma_{4}$ demonstrates a decline in the contemporaneous association between returns and earnings over time.

The second test employs a metric developed by Ali and Hwang (2000) based on Kothari and Sloan (1992). Ali and Hwang run the following return-earnings regressions:

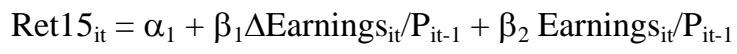


$\operatorname{Ret} 24_{\mathrm{it}}=\alpha_{2}+\gamma_{1} \Delta$ Earnings $_{\mathrm{it}} / \mathrm{P}_{\mathrm{it}-1}+\gamma_{2}$ Earnings $_{\mathrm{it}} / \mathrm{P}_{\mathrm{it}-1}$

The dependent variables are 15 month and 24 month cumulative abnormal returns with return windows ending three months after the end of the fiscal year of the firm. The independent variables are changes in earnings per share and earnings per share scaled by beginning of period price. Similar to Ali and Zarowin (1992), the earnings response coefficient (ERC) is computed for each equation as the sum of the coefficients on earnings and the change in earnings $\left(\mathrm{ERC}_{24}=\gamma_{1}+\gamma_{2}\right.$ and $\left.\mathrm{ERC}_{15}=\beta_{1}+\beta_{2}\right)$. According to Kothari and Sloan, if prices do not lead earnings, $\mathrm{ERC}_{15}$ and $\mathrm{ERC}_{24}$ should not be significantly different. This is due to the fact that prior period returns do not contain any additional information about current period earnings. If, however, there is information in earnings which was impounded into prior period returns, then $\mathrm{ERC}_{24}>\mathrm{ERC}_{15}$. Ali and Hwang construct the following leadlag (LL) statistic as a continuous measure of the degree to which prices lead earnings:

LL statistic $=\mathrm{ERC}_{15} / \mathrm{ERC}_{24}$

During periods when prices lead earnings, this metric obtains a value less than one as $\mathrm{ERC}_{24}>\mathrm{ERC}_{15}$. As the degree to which prices lead earnings increases, $\mathrm{ERC}_{24}$ increases and the LL statistic decreases. This statistic is computed and tested for temporal changes by utilizing the following regression:

LL statistic ${ }_{\mathrm{t}}=\alpha_{0}+\alpha_{1} \mathrm{TIME}_{\mathrm{t}}+\varepsilon_{\mathrm{t}}$

Significance on $\alpha_{1}$ indicates a change in the LL statistic over time, and therefore the degree to which the lack of timeliness of earnings has changed over time.

\section{Controlling for Timeliness}

Ali and Hwang (2000) developed a methodology to control for differential lead-lag environments on the contemporaneous association between returns and earnings. They divide the R-squared from contemporaneous returns-earnings regressions by the LL statistic to develop a transformed measure of the explanatory power of earnings. Thus, firms in which prices lead earnings to a greater degree will obtain an R-squared that is biased toward zero and a LL statistic of lower magnitude. This produces a transformed R-squared that is larger than the original value. ${ }^{4}$ To demonstrate consistency with prior literature, the original R-squared is regressed on TIME. Given that the transformed R-squared has been controlled for the lack of timeliness effect, regressing it on TIME will indicate the effect of transitory earnings and value-irrelevant noise on the inter-temporal decline in the contemporaneous association between returns (prices) and earnings.

\section{Controlling for Transitory Earnings}

When bottom line earnings is used in the analysis, these tests can determine whether lack of timeliness, as well as value-irrelevant noise and transitory earnings, together contribute to the decline in the contemporaneous association between returns (prices) and earnings. To examine whether value-irrelevant noise, by itself, contributes to the decline in the contemporaneous association, the previous analysis is repeated using CORE earnings. For the CORE earnings measure, a decline in the contemporaneous association, after controlling for lack of timeliness, is consistent with value-irrelevant noise contributing to the inter-temporal decline in the contemporaneous association between returns (prices) and earnings.

\section{SAMPLE AND RESULTS}

\section{Sample}

All financial statement data are drawn from the Compustat database using all firm observations available on the 1999 PST, FULL and Research tapes. For the temporal analysis, this includes data from 1958 through 1998. The returns and security prices are drawn from CRSP. To maintain comparability of results across tests, restrictions

${ }^{4}$ Ali and Hwang (2000) acknowledge that this adjustment is somewhat ad hoc. 
for all tests were imposed on available data to obtain one data set. The restrictions include outlier deletion procedures used by Collins et al. (1997) and Ali and Zarowin (2000) resulting in 111,882 firm year observations utilized in Tables 2-4. Additional restrictions used by Collins and Kothari (1989) were included, such as December year ends and NYSE listing, resulting in 27,719 observations utilized in Table 1.

\section{Inter-Temporal Change in Lack of Timeliness}

Table 1 presents the results of the estimation of Equation (1) and Equation (2). Similar to Collins and Kothari (1989), each equation is estimated for the aggregate sample as well as for three equally sized groups partitioned on market value of equity. For each size partition, a ratio of the coefficient on prior period returns and the coefficient on the contemporaneous returns is presented. Collins and Kothari argue that this ratio should be increasing in firm size due to differentials in the information environments of the firm groups. Each test in this study will similarly be examined for differential effects across size groups. There are no ex-ante expectations with regard to potential differential effects across these groups.

Table 1: Pooled Time Series Cross-Sectional Regression of Earnings Changes on Contemporaneous and Lagged Security Returns Along with TIME Interactions

\begin{tabular}{|c|c|c|c|c|c|c|c|}
\hline \multicolumn{8}{|c|}{$\begin{array}{l}\text { Original Equation (Collins and Kothari 1989): } \Delta \mathrm{X}_{\mathrm{t}} / \mathrm{P}_{\mathrm{t}-1}=\alpha_{0}+\alpha_{1} \mathrm{R}_{\mathrm{i}, \mathrm{t}-1}+\alpha_{2} \mathrm{R}_{\mathrm{i}, \mathrm{t}}+\mu_{\mathrm{i}, \mathrm{t}} \\
\text { Modified Equation: } \Delta \mathrm{X}_{\mathrm{i}, \mathrm{t}} / \mathrm{P}_{\mathrm{i}, \mathrm{t}-1}=\gamma_{0}+\gamma_{1} \mathrm{R}_{\mathrm{i}, \mathrm{t}-1}+\gamma_{2} \mathrm{R}_{\mathrm{i}, \mathrm{t}}+\gamma_{3} \mathrm{TIME} * \mathrm{R}_{\mathrm{i}, \mathrm{t}-1}+\gamma_{4} \mathrm{TIME} * \mathrm{R}_{\mathrm{i}, \mathrm{t}}+\sum \gamma_{5, \mathrm{t}} \text { Year }_{\mathrm{i}, \mathrm{t}}+\varepsilon_{\mathrm{it}}\end{array}$} \\
\hline \multicolumn{8}{|c|}{ Panel A: Original Equation } \\
\hline Firm Size & $\mathbf{N}$ & $\alpha_{0}$ t-stat & \multicolumn{2}{|c|}{$\alpha_{1}$ t-stat } & $\alpha_{2}$ t-stat & Adj. $\mathbf{R}^{2}$ & $\alpha_{1} / \alpha_{2}$ \\
\hline \multirow{2}{*}{ All } & 27719 & $-0.0389 *$ & \multicolumn{2}{|c|}{$0.0084 *$} & $0.0480 *$ & $9.53 \%$ & \\
\hline & & -6.42 & \multicolumn{2}{|c|}{8.10} & 44.54 & & \\
\hline \multirow[t]{2}{*}{ Small } & 9227 & $-0.0561 *$ & \multicolumn{2}{|c|}{$0.0089 *$} & $0.0661 *$ & $14.24 \%$ & 0.1350 \\
\hline & & -4.35 & \multicolumn{2}{|c|}{4.72} & 34.62 & & \\
\hline \multirow[t]{2}{*}{ Medium } & 9252 & $-0.0315 *$ & \multicolumn{2}{|c|}{$0.0096^{*}$} & $0.0353 *$ & $7.43 \%$ & 0.2727 \\
\hline & & -3.28 & \multicolumn{2}{|c|}{5.72} & 19.90 & & \\
\hline \multirow[t]{2}{*}{ Large } & 9240 & $-0.0240 *$ & \multicolumn{2}{|c|}{$0.0072 *$} & $0.0275^{*}$ & $5.58 \%$ & 0.2603 \\
\hline & & -2.86 & \multicolumn{2}{|c|}{4.11} & 14.10 & & \\
\hline \multicolumn{8}{|c|}{ Panel B: Modified Equation } \\
\hline Firm Size & $\mathbf{N}$ & $\gamma_{0}$ t-stat & $\gamma_{1}$ t-stat & $\gamma_{2}$ t-stat & $\gamma_{3}$ t-stat & $\gamma_{4}$ t-stat & Adj. $R^{2}$ \\
\hline \multirow[t]{2}{*}{ All } & 27719 & $-0.0434 *$ & -0.0009 & $0.0576^{*}$ & $0.0003^{*}$ & $-0.0003 *$ & $9.57 \%$ \\
\hline & & -6.94 & -0.25 & 16.61 & 2.75 & -2.91 & \\
\hline \multirow[t]{2}{*}{ Small } & 9227 & $-0.0667 *$ & -0.0080 & $0.0873 *$ & $0.0006^{*}$ & $-0.0007 *$ & $14.40 \%$ \\
\hline & & -5.04 & -1.28 & 14.06 & 2.81 & -3.58 & \\
\hline \multirow[t]{2}{*}{ Medium } & 9252 & $-0.0314 *$ & 0.0031 & $0.0354 *$ & 0.0002 & 0.0000 & $7.42 \%$ \\
\hline & & -3.14 & 0.51 & 6.11 & 1.15 & 0.00 & \\
\hline \multirow[t]{2}{*}{ Large } & 9240 & $-0.0235^{*}$ & 0.0084 & $0.0264 *$ & 0.0000 & 0.0000 & $5.56 \%$ \\
\hline & & -2.69 & 1.41 & 4.25 & -0.22 & 0.20 & \\
\hline
\end{tabular}

* Indicates that the coefficient is statistically significant at $\mathrm{p}<0.01$.

Variable definitions: $\Delta X_{t}$ is the change in earnings computed as the difference between earnings in year $t$ and earnings in year $t-1 . P_{t-1}$ is the per share stock price at the beginning of year $t . R_{t}$ is the 12-month cumulative abnormal returns ending in March of year $t+1$ and $\mathrm{R}_{\mathrm{t}-1}$ is the 12-month cumulative abnormal returns ending in March of year $\mathrm{t}$. TIME takes on values from 1 to $\mathrm{T}$ where $\mathrm{T}$ is the number of sample years. Year represents a vector of year dummy variables from 1958 to 1998.

The results for the estimation of equation (1), Panel A, are consistent with Collins and Kothari (1989). For the full sample, the coefficients on prior period returns $(0.0084, \mathrm{t}=8.10)$ and contemporaneous returns $(0.0480, \mathrm{t}=$ 44.54) are positive and significant. The significant coefficient on the prior period returns illustrates that prices lead earnings. This result holds for each of the size partitions as significant, positive coefficients are obtained for the small $\left(\alpha_{1}=0.0089, \mathrm{t}=4.72 ; \alpha_{2}=0.0661, \mathrm{t}=34.62\right)$, medium $\left(\alpha_{1}=0.0096, \mathrm{t}=5.72 ; \alpha_{2}=0.0353, \mathrm{t}=19.90\right)$ and large $\left(\alpha_{1}=0.0072, \mathrm{t}=4.11 ; \alpha_{2}=0.0275, \mathrm{t}=14.10\right)$ groups, indicating that the lead-lag relationship holds for all firm sizes. The ratio of the coefficients is increasing in size - from 0.1350 in the small group to 0.2603 in the large group. These findings are consistent with Collins and Kothari (1989). 
The results for the modified equation are presented in Panel B. For the aggregate sample, the prior period return interaction $\left(\gamma_{3}\right)$ obtains a significant, positive coefficient $(0.0003, t=2.75)$. The positive coefficient indicates an inter-temporal increase in the association between earnings and prior period returns and therefore an increase in the degree to which prices lead earnings. The contemporaneous interaction $\left(\gamma_{4}\right)$ obtains a significant, negative coefficient $(-0.0003, \mathrm{t}=-2.91)$. This result indicates a decline in the contemporaneous relationship between returns and earnings consistent with prior literature. The combined result suggests a shift in the timing of the market acquiring information and impounding it into prices. This could be due to changes in the timing of information acquisition or the use of a more sophisticated estimation technique to anticipate future earnings. When the size partitions in Panel B are examined, only the small size group obtains significant results. For the small firms, the prior period interaction obtains a significant, positive coefficient $(0.0006, \mathrm{t}=2.81)$ and the contemporaneous interaction obtains a significant, negative coefficient $(-0.0007, \mathrm{t}=-3.58)$. This indicates that the lack of timeliness of earnings is increasing predominantly in smaller firms. This result is consistent with the argument that large firms begin with a greater lack of timeliness; consequently, there is less room for an increase over time as compared to small firms.

Table 2 provides estimation results testing for inter-temporal changes in the LL statistic. Panel A presents the results of regressions of the LL statistic on TIME using bottom line earnings. In Panel A, the aggregate sample obtains a significant, negative coefficient on TIME $(-0.0080, t=-3.62)$ providing further evidence of an increase in the degree to which prices lead earnings. The coefficient on TIME for the small $(-0.0092, t=-3.16)$ and medium $(-0.0284, \mathrm{t}=-4.70)$ size groups are negative and significant while the large group $(-0.0123, \mathrm{t}=-1.10)$ is not significant, suggesting that lack of timeliness for larger firms has not significantly changed over time. The results in Table 3 are consistent with the evidence provided in Table 2.

Table 2: Results of LL Statistic Regressed Upon TIME

\begin{tabular}{|c|c|c|c|c|}
\hline \multicolumn{5}{|c|}{$\begin{array}{l}\text { LL statistic }{ }_{\mathrm{t}}=\alpha_{0}+\alpha_{1} \mathrm{TIME}_{\mathrm{t}}+\varepsilon_{\mathrm{t}} \\
\text { Panel A: Using Bottom Line Earnings }\end{array}$} \\
\hline Firm Size & $\mathbf{N}$ & $\alpha_{0}$ t-stat & $\alpha_{1}^{a}$ t-stat & Adj. $\mathbf{R}^{2}$ \\
\hline \multirow[t]{2}{*}{ All } & 41 & $1.1542 *$ & $-0.0080 *$ & $27.77 \%$ \\
\hline & & 20.87 & -3.62 & \\
\hline \multirow[t]{2}{*}{ Small } & 41 & $0.9834^{*}$ & $-0.0092 *$ & $19.23 \%$ \\
\hline & & 13.55 & -3.16 & \\
\hline \multirow[t]{2}{*}{ Medium } & 41 & $2.0754 *$ & $-0.0284 *$ & $37.38 \%$ \\
\hline & & 13.72 & -4.70 & \\
\hline \multirow[t]{2}{*}{ Large } & 41 & $1.4190^{*}$ & -0.0123 & $18.29 \%$ \\
\hline & & 5.05 & -1.10 & \\
\hline \multicolumn{5}{|c|}{ Panel B: Using CORE Earnings } \\
\hline Firm Size & $\mathbf{N}$ & $\alpha_{0}$ t-stat & $\alpha_{1}{ }^{a}$ t-stat & Adj. $\mathbf{R}^{2}$ \\
\hline \multirow[t]{2}{*}{ All } & 41 & $1.1625^{*}$ & $-0.0080 *$ & $29.81 \%$ \\
\hline & & 16.51 & -2.86 & \\
\hline \multirow[t]{2}{*}{ Small } & 41 & $1.0916^{*}$ & $-0.0136^{*}$ & $30.55 \%$ \\
\hline & & 9.01 & -2.82 & \\
\hline \multirow[t]{2}{*}{ Medium } & 41 & $1.8094 *$ & $-0.0155^{*}$ & $14.49 \%$ \\
\hline & & 12.67 & -2.72 & \\
\hline \multirow[t]{2}{*}{ Large } & 41 & $1.2537 *$ & 0.0017 & $10.93 \%$ \\
\hline & & 3.86 & 0.13 & \\
\hline
\end{tabular}

* Indicates that the coefficient is statistically significant at $\mathrm{p}<0.01 .{ }^{\mathrm{a}}$ All of the above regressions were corrected for first-order autocorrelation in the residuals using a generalized least-squares approach developed by Prais and Winston (1954).

Variable definitions: LL statistic $=$ ERC15/ERC24. The ERCs are estimated from the model $\operatorname{Ret}_{\mathrm{t}}=\alpha_{0}+\alpha_{1}$ $\Delta \mathrm{X}_{\mathrm{it}} / \mathrm{P}_{\mathrm{it}-1}+\alpha_{2} \mathrm{X}_{\mathrm{it}} / \mathrm{P}_{\mathrm{it}-1}+\varepsilon_{\mathrm{it}}$ where $\mathrm{Ret}_{\mathrm{t}}$ is 15 -month cumulative abnormal returns ending three months after the end of the fiscal year, $\Delta \mathrm{X}_{\mathrm{t}}$ is the change in earnings computed as the difference between earnings in year $t$ and earnings in year $\mathrm{t}-1, \mathrm{X}_{\mathrm{t}}$ is earnings in year $\mathrm{t}$, and $\mathrm{P}_{\mathrm{t}-1}$ is the per share stock price at the beginning of year $\mathrm{t}$. ERC15 is computed as the sum of $\alpha_{1}$ and $\alpha_{2}$ using 15-month cumulative abnormal returns ending three months after the end of the fiscal year and ERC24 is computed as the sum of $\alpha_{1}$ and $\alpha_{2}$ using 24-month cumulative abnormal returns ending three months after the end of the fiscal year. TIME takes on values from 1 to $\mathrm{T}$ where $\mathrm{T}$ is the number of sample years. 
Panel B uses CORE earnings and provides results consistent with Panel A. The aggregate sample obtains a significant, negative coefficient on TIME $(-0.0080, \mathrm{t}=-2.86)$ providing further evidence of an increase in the degree to which prices lead earnings. The coefficient for the small $(-0.0136, \mathrm{t}=-2.82)$ and medium $(-0.0155, \mathrm{t}=-2.72)$ size groups are negative and significant, while the large group $(0.0017, \mathrm{t}=0.13)$ is not. Thus, the aggregate sample results in Tables 2 and 3 reject the null hypothesis $\mathrm{H} 1$ which states that changes in the lack of timeliness of earnings does not contribute to the observed inter-temporal decline in the contemporaneous association between returns (prices) and earnings.

\section{Inter-Temporal Changes in Value-Irrelevant Noise and Transitory Earnings}

Table 3 presents the results of R-squared and transformed R-squared (adjusted for the lack of timeliness) on TIME; the R-squared is the explanatory power of the contemporaneous return-earnings regressions. Panel A provides the results for these estimates using bottom line earnings. The estimation of the full sample using the original R-squared obtains a significant, negative coefficient on TIME $(-0.0027, t=-4.27)$, demonstrating an intertemporal decline in the contemporaneous association between returns and earnings. These findings are consistent with those reported in Lev and Zarowin (1999). This result holds for all three size partitions with the small (-0.0067, $\mathrm{t}=-6.13)$, medium $(-0.0048, \mathrm{t}=-7.09)$, and large $(-0.0028, \mathrm{t}=-2.02)$ groups obtaining significant, negative coefficients. This indicates the decline is not specific to one size partition.

Table 3: Results of $\mathbf{R}^{2}$ from Return-Earnings Regressions Regressed Upon TIME

$\mathrm{R}_{\mathrm{t}}^{2}=\alpha_{0}+\alpha_{1} \mathrm{TIME}_{\mathrm{t}}+\varepsilon_{\mathrm{t}}$

\section{Panel A: Using Bottom Line Earnings}

\begin{tabular}{|c|c|c|c|c|c|c|c|}
\hline \multirow[b]{2}{*}{ Firm Size } & \multirow[b]{2}{*}{$\mathbf{N}$} & \multicolumn{3}{|c|}{ Dependent Variable: $\mathbf{R}^{2}$} & \multicolumn{3}{|c|}{ Dependent Variable: Transformed $\mathbf{R}^{2}$} \\
\hline & & $\alpha_{0}$ t-stat & $\alpha_{1}^{\mathrm{a}}$ t-stat & Adj. $\mathbf{R}^{2}$ & $\alpha_{0}$ t-stat & $\alpha_{1}^{a}$ t-stat & Adj. $R^{2}$ \\
\hline \multirow[t]{2}{*}{ All } & 41 & $0.1628^{*}$ & $-0.0027^{*}$ & $29.62 \%$ & $0.1529 *$ & $-0.0021^{*}$ & $18.34 \%$ \\
\hline & & 10.38 & -4.27 & & 8.64 & -2.97 & \\
\hline \multirow[t]{2}{*}{ Small } & 41 & $0.299 *$ & $-0.0067 *$ & $46.65 \%$ & $0.2675^{*}$ & $-0.0054 *$ & $44.05 \%$ \\
\hline & & 10.90 & -6.13 & & 12.05 & -6.07 & \\
\hline \multirow[t]{2}{*}{ Medium } & 41 & $0.2335^{*}$ & $-0.0048 *$ & $51.31 \%$ & $0.2177 *$ & $-0.0040^{*}$ & $38.32 \%$ \\
\hline & & 13.92 & -7.09 & & 11.92 & -5.44 & \\
\hline \multirow[t]{2}{*}{ Large } & 41 & $0.1553^{*}$ & $-0.0028 * * *$ & $15.27 \%$ & $0.1490 *$ & -0.0023 & $7.97 \%$ \\
\hline & & 4.48 & -2.02 & & 4.22 & -1.64 & \\
\hline
\end{tabular}

Panel B: Using CORE Earnings

\begin{tabular}{|c|c|c|c|c|c|c|c|}
\hline \multirow{2}{*}{ Firm Size } & \multirow[b]{2}{*}{$\mathbf{N}$} & \multicolumn{3}{|c|}{ Dependent Variable $^{a}: \mathbf{R}^{2}$} & \multicolumn{3}{|c|}{ Dependent Variable $^{\mathrm{a}}: \mathbf{R}^{2}$} \\
\hline & & $\alpha_{0}$ t-stat & $\alpha_{1}^{a}$ t-stat & Adj. $R^{2}$ & $\alpha_{0}$ t-stat & $\alpha_{1}{ }^{a}$ t-stat & Adj. $\mathbf{R}^{2}$ \\
\hline \multirow[t]{2}{*}{ All } & 41 & $0.1766^{*}$ & $-0.0032 *$ & $36.00 \%$ & 0.1687 * & $-0.0027 *$ & $23.25 \%$ \\
\hline & & 11.21 & -5.03 & & 8.88 & -3.54 & \\
\hline \multirow[t]{2}{*}{ Small } & 41 & $0.3273 *$ & $-0.0078^{*}$ & $50.50 \%$ & $0.2938^{*}$ & $-0.0065^{*}$ & $48.72 \%$ \\
\hline & & 10.85 & -6.45 & & 12.15 & -6.69 & \\
\hline \multirow[t]{2}{*}{ Medium } & 41 & $0.2412 *$ & $-0.0047 *$ & $43.01 \%$ & $0.2265 *$ & $-0.0039 *$ & $29.17 \%$ \\
\hline & & 11.39 & -5.54 & & 9.61 & -4.15 & \\
\hline \multirow[t]{2}{*}{ Large } & 41 & $0.1694 *$ & $-0.0028 * * *$ & $16.81 \%$ & $0.1685^{*}$ & -0.0025 & $9.54 \%$ \\
\hline & & 4.39 & -1.84 & & 4.11 & -1.53 & \\
\hline
\end{tabular}

$*, * *, * * *$ Indicates that the coefficient is significant at $(\mathrm{p}<0.01),(\mathrm{p}<0.05)$ and $(\mathrm{p}<0.10)$, respectively. ${ }^{a}$ All of the above regressions were corrected for first-order autocorrelation in the residuals using a generalized least-squares approach developed by Prais and Winston (1954).

Variable definitions: $\mathrm{R}^{2}$ is from estimating $\operatorname{Ret}_{\mathrm{t}}=\alpha_{0}+\alpha_{1} \Delta \mathrm{X}_{\mathrm{it}} / \mathrm{P}_{\mathrm{it}-1}+\alpha_{2} \mathrm{X}_{\mathrm{it}} / \mathrm{P}_{\mathrm{it}-1}+\varepsilon_{\mathrm{it}}$ where $\operatorname{Ret}_{\mathrm{t}}$ is 15 -month cumulative abnormal returns ending three months after the end of the fiscal year, $\Delta \mathrm{X}_{\mathrm{t}}$ is the change in earnings computed as the difference between earnings in year $t$ and earnings in year $t-1, X_{t}$ is earnings in year $t$ and $P_{t-1}$ is the per share stock price at the beginning of year $t$. Transformed $R^{2}=R^{2} /(E R C 15 / E R C 24)$ where ERC15 is computed as the sum of $\alpha_{1}$ and $\alpha_{2}$ using 15 month cumulative abnormal returns ending three months after the end of the fiscal year and ERC24 is computed as the sum of $\alpha_{1}$ and $\alpha_{2}$ using 24 month cumulative abnormal returns ending three months after the end of the fiscal year. TIME takes on values from 1 to $\mathrm{T}$ where $\mathrm{T}$ is the number of sample years.

The transformed R-squared results using bottom line earnings provide an indication of the effect of both transitory earnings and value-irrelevant noise on the contemporaneous association between returns (prices) and 
earnings. The coefficient on TIME for the full sample is negative and significant $(-0.0021, \mathrm{t}=-2.97)$ as are the coefficients for the small $(-0.0054, \mathrm{t}=-6.07)$ and medium $(-0.0040, \mathrm{t}=-5.44)$ size groups. The large size group obtains insignificant results $(-0.0023, \mathrm{t}=-1.64)$. Overall, the results reject $\mathrm{H} 2$ which states that changes in valueirrelevant noise and transitory earnings over time are not responsible for the observed inter-temporal decline in the contemporaneous return (price) earnings association.

\section{Inter-Temporal Changes in Value-Irrelevant Noise}

Table 3 Panel B provides the results using CORE earnings. The estimation of the full sample using the untransformed R-squared obtains a significant, negative coefficient on TIME $(-0.0032, t=-5.03)$, demonstrating an inter-temporal decline in the association between returns and CORE earnings. Similar to Panel A, this result holds for all three size partitions with the small $(-0.0078, \mathrm{t}=-6.45)$, medium $(-0.0047, \mathrm{t}=-5.54)$, and large $(-0.0028$, $\mathrm{t}=-1.84$ ) groups obtaining significant, negative coefficients.

The transformed R-squared results provide an indication of the effect of value-irrelevant noise alone on the contemporaneous association between returns (prices) and earnings. The coefficient on TIME for the full sample is negative and significant $(-0.0027, \mathrm{t}=-3.54)$. Similar to Panel $\mathrm{A}$, this result does not hold for all size partitions as the small $(-0.0065, \mathrm{t}=-6.69)$ and medium $(-0.0039, \mathrm{t}=-4.15)$ size groups obtain significant, negative coefficients and the large size group $(-0.0025, \mathrm{t}=-1.53)$ obtains insignificant results. Overall, the results reject $\mathrm{H} 3$ which states that value-irrelevant noise, by itself, does not contribute to the inter-temporal decline in the contemporaneous return (price)-earnings association.

\section{Results for Incremental Explanatory Power of Earnings}

The results presented so far are for the explanatory power of earnings for returns. Collins et al. (1997) examines the incremental explanatory power of earnings beyond book value in a price model. The above analysis is repeated for this measure of the explanatory power of earnings. Panel A in Table 4 provides results using bottom line earnings. Estimation using the full sample yields a significant, negative coefficient $(-0.0059, \mathrm{t}=-4.47)$. This finding holds for the small $(-0.0044, \mathrm{t}=-5.06)$, medium $(-0.0060, \mathrm{t}=-5.68)$, and large $(-0.0056, \mathrm{t}=-5.08)$ size partitions which all obtain significant, negative coefficients. This result suggests an inter-temporal decline in the incremental explanatory power of earnings consistent with the findings of Collins et al. (1997). After controlling for the lack of timeliness effect, a significant, negative coefficient on TIME for the full sample $(-0.0053, \mathrm{t}=-4.08)$ persists. This result holds for all size partitions as the small $(-0.0038, \mathrm{t}=-4.54)$, medium $(-0.0053, \mathrm{t}=-4.46)$, and large $(-0.0045, \mathrm{t}=-4.08)$ size groups obtain significant, negative coefficients. These results reject $\mathrm{H} 2 \mathrm{which}$ states that transitory earnings and value-irrelevant noise do not contribute to the inter-temporal decline in the contemporaneous price-earnings association.

Table 4: Results of Incremental Explanatory Power of Earnings (From Price-Earnings and Book Values Regression) Regressed on TIME

\begin{tabular}{|c|c|c|c|c|c|c|c|}
\hline \multicolumn{8}{|c|}{$\mathrm{R}_{\mathrm{t}}^{2}=\alpha_{0}+\alpha_{1} \mathrm{TIME}_{\mathrm{t}}+\varepsilon_{\mathrm{t}}$} \\
\hline \multicolumn{8}{|c|}{ Panel A: Using Bottom Line Earnings } \\
\hline & & \multicolumn{3}{|c|}{ Dependent Variable: $\mathbf{R}^{2}$} & \multicolumn{3}{|c|}{ Dependent Variable: Transformed $\mathbf{R}^{2}$} \\
\hline Firm Size & $\mathbf{N}$ & $\alpha_{0}$ t-stat & $\alpha_{1}^{a}$ t-stat & Adj. $R^{2}$ & $\alpha_{0}$ t-stat & $\alpha_{1}{ }^{a}$ t-stat & Adj. $R^{2}$ \\
\hline \multirow[t]{2}{*}{ All } & 41 & $0.2831 *$ & $-0.0059 *$ & $87.94 \%$ & $0.2730 *$ & $-0.0053^{*}$ & $78.29 \%$ \\
\hline & & 8.33 & -4.47 & & 8.25 & -4.08 & \\
\hline \multirow[t]{2}{*}{ Small } & 41 & $0.1878 *$ & $-0.0044 *$ & $58.26 \%$ & $0.1739 *$ & $-0.0038 *$ & $57.99 \%$ \\
\hline & & 8.64 & -5.06 & & 8.22 & -4.54 & \\
\hline \multirow[t]{2}{*}{ Medium } & 41 & $0.2875^{*}$ & $-0.0060 *$ & $77.88 \%$ & $0.2755^{*}$ & $-0.0053 *$ & $64.57 \%$ \\
\hline & & 10.77 & -5.68 & & 9.15 & -4.46 & \\
\hline \multirow[t]{2}{*}{ Large } & 41 & $0.2856^{*}$ & $-0.0056^{*}$ & $68.51 \%$ & $0.2649 *$ & $-0.0045^{*}$ & $56.11 \%$ \\
\hline & & 10.27 & -5.08 & & 9.48 & -4.08 & \\
\hline
\end{tabular}


Table 4 cont.

\begin{tabular}{|c|c|c|c|c|c|c|c|}
\hline \multicolumn{8}{|c|}{ Panel B: Using CORE Earnings } \\
\hline & & \multicolumn{3}{|c|}{ Dependent Variable: $\mathbf{R}^{2}$} & \multicolumn{3}{|c|}{ Dependent Variable: Transformed $\mathbf{R}^{2}$} \\
\hline Firm Size & $\mathbf{N}$ & $\alpha_{0}$ t-stat & $\alpha_{1}{ }^{a}$ t-stat & Adj. $\mathbf{R}^{2}$ & $\alpha_{0}$ t-stat & $\alpha_{1}{ }^{a}$ t-stat & Adj. $\mathbf{R}^{2}$ \\
\hline \multirow[t]{2}{*}{ All } & 41 & $0.2851 *$ & $-0.0054 *$ & $85.89 \%$ & $0.2766^{*}$ & $-0.0048 *$ & $72.65 \%$ \\
\hline & & 6.81 & -3.34 & & 6.73 & -3.01 & \\
\hline \multirow[t]{2}{*}{ Small } & 41 & $0.2147 *$ & $-0.0050 *$ & $60.12 \%$ & $0.1964 *$ & $-0.0043 *$ & $57.75 \%$ \\
\hline & & 10.39 & -6.03 & & 10.05 & -5.45 & \\
\hline \multirow[t]{2}{*}{ Medium } & 41 & $0.2877 *$ & $-0.0058 *$ & $75.49 \%$ & $0.2732 *$ & $-0.0050^{*}$ & $59.70 \%$ \\
\hline & & 10.45 & -5.36 & & 8.59 & -3.99 & \\
\hline \multirow[t]{2}{*}{ Large } & 41 & $0.2861 *$ & $-0.0052 *$ & $62.59 \%$ & $0.2667 *$ & $-0.0041^{*}$ & $47.30 \%$ \\
\hline & & 8.58 & -3.93 & & 7.47 & -2.92 & \\
\hline
\end{tabular}

* Indicates that the coefficient is significant at $\mathrm{p}<0.01$. ${ }^{\mathrm{a}}$ All of the above regressions were corrected for first-order autocorrelation in the residuals using a generalized least-squares approach developed by Prais and Winston (1954).

Variable definitions: $R^{2}=R_{T}^{2}-R_{B}^{2}$ where $R_{T}^{2}$ is the estimated $R^{2}$ from the model $P_{i t}=\alpha_{0}+\alpha_{1} X_{i t}+\alpha_{2} B V_{i t}$ $+\varepsilon_{\text {it }}$ and $R_{B}^{2}$ is the estimated $R^{2}$ from the model $P_{i t}=\alpha_{0}+\alpha_{1} B V_{i t}+\varepsilon_{i t} . P_{i t}$ is the per share stock price three months after the end of the fiscal year, $\mathrm{X}_{\mathrm{t}}$ is the earnings per share, and $\mathrm{BV}_{\mathrm{t}}$ is the book value per share. Transformed $\mathrm{R}^{2}=$ $\mathrm{R}^{2}$ /(ERC15/ERC24) where ERC15 is computed as the sum of $\alpha_{1}$ and $\alpha_{2}$ using 15-month cumulative abnormal returns ending three months after the end of the fiscal year and ERC24 is computed as the sum of $\alpha_{1}$ and $\alpha_{2}$ using 24-month cumulative abnormal returns ending three months after the end of the fiscal year. TIME takes on values from 1 to $\mathrm{T}$ where $\mathrm{T}$ is the number of sample years.

Table 4 Panel B results are based on CORE earnings. The estimation of the full sample using the incremental explanatory power of CORE earnings obtains a significant, negative coefficient on TIME $(-0.0054$, $\mathrm{t}=-3.34)$. This result holds for all three size partitions with the small $(-0.0050, \mathrm{t}=-6.03)$, medium $(-0.0058$, $\mathrm{t}=-5.36)$, and large $(-0.0052, \mathrm{t}=-3.93)$ groups obtaining significant, negative coefficients. The transformed $\mathrm{R}-$ squared results provide an indication of the effect of value-irrelevant noise alone on the contemporaneous association between prices and earnings. For the full sample, TIME obtains a significant, negative coefficient $(-0.0048, \mathrm{t}=-3.01)$. This results holds for all size partitions as the small $(-0.0043, \mathrm{t}=-5.45)$, medium $(-0.0050$, $\mathrm{t}=-3.99)$, and large $(-0.0041, \mathrm{t}=-2.92)$ size groups obtain significant, negative coefficients. These results reject $\mathrm{H} 3$ which states that value-irrelevant noise alone does not contribute to the inter-temporal decline in the price-earnings association.

\section{SUMMARY AND CONCLUSIONS}

This study examines which factors contribute to the documented inter-temporal decline in the contemporaneous association between returns (prices) and earnings, specifically three factors identified by Collins, Kothari, Shanken, and Sloan (1994) and Kothari (2000) - lack of timeliness, noise in earnings, and transitory earnings. The findings indicate that there has been an increase in the lack of timeliness of earnings over time. After controlling for the lack of timeliness factor, there remains a significant inter-temporal decline in the explanatory power of earnings for contemporaneous returns (prices). This evidence suggests that changes in value-irrelevant noise and transitory components in earnings contribute to the documented decline in the contemporaneous association between returns (prices) and earnings. When CORE earnings are used to control for transitory earnings, value-irrelevant noise, by itself, also appears to contribute to the inter-temporal decline in the association between returns (prices) and earnings.

Based upon the evidence of an inter-temporal decline in the contemporaneous association between returns (prices) and earnings, Lev and Zarowin (1999) conclude that they have documented a systematic decline in the "usefulness of financial information to investors" and that current reporting requirements suffer from "inadequacies" which "may adversely affect investors' and firms' welfare." If lack of timeliness or transitory earnings were the only factors responsible for the decline in the contemporaneous association, then some (eg. Collins, Kothari, Shanken, and Sloan 1994), would argue that current reporting requirements need not be changed. This study presents evidence of an increase in value-irrelevant noise as a contributor to the declining contemporaneous association, which may support a call for considering changes to current financial reporting requirements. 


\section{AUTHOR INFORMATION}

L. Dwight Sneathen Jr. is an Associate Professor at Georgia Southern University. He teaches in the area of financial accounting at both undergraduate and graduate level. His research includes capital markets and audit topics focusing on the impact of firm characteristics on audit planning decisions and outcomes. E-mail: dsneathen@georgiasouthern.edu

\section{REFERENCES}

1. Ali, A., and L. Hwang. (2000). Country-Specific Factors Related to Financial Reporting and the Value Relevance of Accounting Data. Journal of Accounting Research, 38(Spring), 1-21.

2. Ali, A., and P. Zarowin. (1992). The Role of Earnings Levels in Annual Earnings-Returns Studies, Journal of Accounting Research, 30(Autumn), 286-296.

3. Ayers, B. C., and R. N. Freeman. (2003). Evidence that Analyst Following and Institutional Ownership Accelerate the Pricing of Future Earnings. Review of Accounting Studies, 8, 47-67.

4. Basu, S., (1997). The conservatism principle and the asymmetric timeliness of earnings. Journal of Accounting and Economics, 24, 3-37.

5. Collins, D. W., and S. P. Kothari. (1989). An Analysis of the Inter-temporal and Cross-Sectional Determinants of Earnings Response Coefficients. Journal of Accounting and Economics, 11, 143-181.

6. Collins, D. W., S. P. Kothari, J. Shanken, and R. G. Sloan. (1994). Lack of timeliness and noise as explanations for the low contemporaneous return-earnings association. Journal of Accounting and Economics, 18, 289-324.

7. Collins, D. W., E. L. Maydew, and I. S. Weiss. (1997). Changes in the value-relevance of earnings and book values over the past forty years. Journal of Accounting and Economics, 24, 39-67.

8. Easton, P. D. (1985), Accounting earnings and security valuation: empirical evidence of the fundamental links. Journal of Accounting Research, 23(Supplemental), 54-77.

9. Elliott, J. and J. Hanna. (1996). Repeated accounting write-offs and the information content of earnings. Journal of Accounting Research 34(Supplemental), 135-155.

10. Ely, K. and G. Waymire. (1999). Accounting Standard-Setting Organizations and Earnings Relevance: Longitudinal Evidence From NYSE Common Stocks, 1927-93. Journal of Accounting Research 37(Autumn), 293-317.

11. Francis, J. and K. Schipper. (1999). Have Financial Statements Lost Their Relevance? Journal of Accounting Research 37(Autumn), 319-352.

12. Hayn, C. (1995). The information content of losses. Journal of Accounting and Economics 20, 125-153.

13. Jennings, W. W., K. Schnatterly and P.J. Seguin. (2002). Institutional Ownership, Information and Liquidity, Innovations in Investments and Corporate Finance. Advances in Financial Economics, 7, 41-71.

14. Kothari, S. P. (2001). Capital Markets Research in Accounting. Journal of Accounting and Economics, 31(2001), 105-231.

15. Kothari, S. P. and R. G. Sloan. (1992). Information in prices about future earnings, Implications for earnings response coefficients. Journal of Accounting and Economics 15, 143-171.

16. Kothari, S.P. and J. L. Zimmerman. (1995). Price and return models. Journal of Accounting and Economics $20,155-192$.

17. Lev, B. (1989). On the usefulness of earnings and earnings research: Lessons and directions from two decades of empirical research. Journal of Accounting Research (Supplemental), 153-201.

18. Lev, B. and P. Zarowin. (1999). The Boundaries of Financial Reporting and How to Extend Them. Journal of Accounting Research 37(Autumn), 353-385.

19. Maydew, E. (1997). Tax induced earnings management by firms with net operating losses. Journal of Accounting Research 35(Spring), 83-96.

20. Theil, H. (1971). Principles of Econometrics. Wiley, New York, NY. 


\section{NOTES}

